\title{
Investors' Misreaction to Unexpected Earnings: Evidence of Simultaneous Overreaction and Underreaction*
}

\author{
Michael Kaestner ${ }^{\dagger}$ \\ Preliminary Version - do not quote without permission
}

\begin{abstract}
Behavioral Finance aims to explain empirical anomalies by introducing investor psychology as a determinant of asset pricing. Two kinds of anomalies, namely underreaction and overreaction, have been established by an impressive record of empirical work. While underreaction defines a slow adjustment of prices to corporate events or announcements, overreaction deals with extreme stock price reactions to previous information or past performance. Theoretical models have shown that both phenomena find potential explanations in cognitive biases, that is, investor irrationality.

This study investigates current and past earnings surprises and subsequent market reaction for listed US companies over the period 19831999. The results confirm the existence of post-earnings announcement underreaction and provide new evidence of overreaction to highly unexpected past earnings surprises. Traditionally, unexpected earnings are defined by the difference between the last individual or consensus estimate and the actual, reported earnings per share, standardized by the share price. Other methodologies include scaling by the actual eps or the forecast made. While former is a measure of the market surprise, latter can be considered as the analyst's proportional estimation error. In order to capture the extent to which an earnings surprise is highly unexpected, some of the tests performed in this study use the standard deviation of consensus forecasts as a scaling factor.

The results suggest that investors simultaneously exhibit shortterm underreaction to earnings announcements and long-term overreaction to past highly unexpected earnings. A potential explanation for the reported overreaction phenomenon is the representativeness bias. As I show, the overreaction and the later reversal is stronger for events, which exhibit a long series of similar past earnings surprises.
\end{abstract}

${ }^{*}$ The author received valuable suggestions from Paul Amadieu, Véronique Bessière, Pascal Dumontier, Terrence Odean, Patrick Sentis, Jacques Teulié and Jakob Thomas. Helpful comments from seminar participants at the 2005 AFFI conference, Paris, are gratefully acknowledged. All errors remain the author's responsibility.

${ }^{\dagger}$ GESEM \& CREGO, Montpellier University, kaestner@univ-montp1.fr, kaestner@kwsit.com 


\title{
Investors' Misreaction to Unexpected Earnings: Evidence of Simultaneous Overreaction and Underreaction
}

\begin{abstract}
Behavioral Finance aims to explain empirical anomalies by introducing investor psychology as a determinant of asset pricing. Two kinds of anomalies, namely underreaction and overreaction, have been established by an impressive record of empirical work. While underreaction defines a slow adjustment of prices to corporate events or announcements, overreaction deals with extreme stock price reactions to previous information or past performance. Theoretical models have shown that both phenomena find potential explanations in cognitive biases, that is, investor irrationality.

This study investigates current and past earnings surprises and subsequent market reaction for listed US companies over the period 19831999. The results confirm the existence of post-earnings announcement underreaction and provide new evidence of overreaction to highly unexpected past earnings surprises. Traditionally, unexpected earnings are defined by the difference between the last individual or consensus estimate and the actual, reported earnings per share, standardized by the share price. Other methodologies include scaling by the actual eps or the forecast made. While former is a measure of the market surprise, latter can be considered as the analyst's proportional estimation error. In order to capture the extent to which an earnings surprise is highly unexpected, some of the tests performed in this study use the standard deviation of consensus forecasts as a scaling factor.

The results suggest that investors simultaneously exhibit shortterm underreaction to earnings announcements and long-term overreaction to past highly unexpected earnings. A potential explanation for the reported overreaction phenomenon is the representativeness bias. As I show, the overreaction and the later reversal is stronger for events, which exhibit a long series of similar past earnings surprises.
\end{abstract}

\section{Introduction}

In recent years, Behavioral Finance provided evidence for anomalous stock price behavior and attempted to provide explanations based on not fully rational behavior. Two families of anomalies, namely short-term underreaction and long-term overreaction challenge the traditional view of efficient markets.

This study aims to reconcile short-term underreaction with long-term overreaction in the quarterly earnings announcement framework. Unlike 
other empirical studies related to the Post-Earnings-Drift-Anomaly, I scale unexpected earnings by the consensus forecast standard deviation. This way, I identify highly unexpected surprises, i.e. important positive and negative surprises, that occur for earnings announcements, characterized by a high degree of consensus among analysts. In such a context, representativeness, a bias leading to overreaction, is highly probable. While the tests confirm the classical PEAD underreaction to current surprises, I also find evidence of investor overreaction to previous unexpected earnings. In line with theoretical and experimental findings, this overreaction phenomenon strengthens with the length of similar past surprises.

The paper is organized as follows: the first section provides a short review of Behavioral Finance literature related to overreaction and underreaction. The data and research methodology is exposed in section 2. Section 3 presents the main results regarding short-term underreaction and long-term overreaction to earnings surprises. Section 4 concludes.

\section{Existing evidence of investor misreaction re- garding earnings information}

Since the seminal articles by De Bondt and Thaler (1985) and Jegadeesh and Titman (1993), empirical research in finance has confirmed the existence of two families of pervasive anomalies: short-term underreaction and longterm overreaction. From a theoretical perspective, underreaction defines a situation where individuals fail to react completely and immediately to new information. Overreaction is sometimes mistakenly considered as the opposite phenomenon. Investors excessively react to news, which results in a later reversal. But over- and underreaction do not cancel each other out, for they do not focus on the same underlying information and do not arise in the same context. Underreaction seems to be related to anchoring, and tends to produce effects systematically. Conversely, overreaction may stem from representativeness, which arises only after a series of similar information. ${ }^{1}$ The following subsection briefly reviews empirical and theoretical findings

\footnotetext{
1 "The overreaction evidence shows that over long horizons $[\ldots]$, security prices overreact to consistent patterns of news pointing in the same direction", Shleifer (2000).
} 
related to over- and underreaction.

\subsection{The overreaction phenomenon}

Investors' overreaction to past stock performance seems to be the main conclusion of the seminal De Bondt and Thaler (1985)'s study. The authors rank all stocks traded on the NYSE by their past three year cumulative return. Subsequent abnormal performance turns out to be higher for prior "losers", that is, stocks having experienced the poorest past performance. Over the sub-sequent three years, the bottom decile portfolio yields an abnormal return $8 \%$ higher than that of the top decile portfolio, the prior winners. This reversal suggests that part of an initial overweighing of negative (positive) stock information, driving prices below (over) their rational levels is subsequently corrected. The overreaction phenomenon over long horizons has been confirmed several times on the stock market (De Bondt and Thaler (1987), Chopra, Lakonishok, and Ritter (1992) and more recently Lewellen (2002)), but also for international stock market indices (Chui, Titman, and Wei, 2000; Bhojraj and Swaminathan, 2001), the gold market (Cutler, Poterba, and Summers, 1991) and the options market (Poteshman, 2001).

\subsection{The underreaction phenomenon}

Several studies, beginning with Jegadeesh and Titman (1993) have examined stock price underreaction and possible explanations. In their study, stocks are ranked into portfolios based on their prior six month return. Unlike De Bondt and Thaler (1985)'s finding, prior winners outperform prior losers over the following 6 month period. This "momentum effect" was confirmed by Lee and Swaminathan (2000) and Jegadeesh and Titman (2001). Chan, Hameed, and Tong (2000) examine 23 international stock market indices and report a short-run momentum. Although some methodological issues were mentioned (momentum larger in small firms (Jegadeesh and Titman, 1993; Grinblatt and Moskowitz, 1999) and in growth firms (Daniel and Titman, 1999)), the anomaly has proved robust.

Another large body of literature focuses on stock price underreaction to corporate announcements and events, such as earnings announcements, 
dividend initiations or omissions and public offerings. Since Ball and Brown (1968), the Post-Earnings-Announcement-Drift (PEAD) has become one of the most famous stock market anomalies. Many theories have been advanced to explain the slow adjustment of stock prices to recent and publicly available earnings information. Among them, the role played by individual investors (Hirshleifer, Myers, Myers, and Teoh, 2003), illiquidity issues (Sadka, 2005) and analyst related issues: low analyst coverage (Hong, Lim, and Stein, 2000 ) or analyst underreaction to extreme bad news (Easterwood and Nutt, 1999), causing market underreaction.

\subsection{Simultaneous over- and underreaction}

Evidence of simultaneous over- and underreaction is found in De Bondt and Thaler (1985), where along with long-term overreaction, the authors find that the top one-year decile (the winner portfolio) outperforms the bottom decile (the loser portfolio) ${ }^{2}$. Cutler, Poterba, and Summers (1991) finds positive short-lag autocorrelations and negative autocorrelations at horizons of a few years for 13 stock markets. Similar results of momentum and later reversal were reported in Chui, Titman, and Wei (2000) and Bhojraj and Swaminathan (2001).

While only relatively few empirical studies reported simultaneous overand underreaction, recent theoretical models integrated both phenomena based on cognitive errors, in order to understand if mispricing may be related to cognitive biases. Daniel, Hirshleifer, and Subrahmanyam (1998) propose a model, where overreaction is due to overconfidence whereas self attribution causes underreaction. In Barberis, Shleifer, and Vishny (1998), conservatism and trend chasing cause respectively underreaction and overreaction by integrating two cognitive heuristics: anchoring and representativeness. In Hong and Stein (1999), investors who focus on fundamentals exhibit underreaction, those using market-related information are responsible for overreaction.

\footnotetext{
${ }^{2}$ De Bondt and Thaler (1985), table 1, page 801.
} 


\section{Data and methodology}

\section{$2.1 \quad$ Data}

Financial analysts' earnings forecasts and actual earnings were provided by the I/B/E/S summary file. Return data is obtained from the Center of Research in Security Prices (CRSP) for the period from January, 1st, 1983 until December, 31st, 1999. For each quarterly earnings announcement made by any company over this period, the consensus earnings estimate from the month preceding the earnings announcement and the actual earnings per share (EPS) are collected. The tests of investors' underreaction to the current earnings surprise involve the current EPS measure $\left(E P S_{c}\right)$ and the latest consensus forecast made in the month preceding the earnings announcement $\left(E S T_{c}\right)$. For each earnings announcement, return data for the announcement day and the 60 trading days following the actual announcement date was extracted from CRSP. Quarterly earnings, earnings announcement dates and estimates were not available for all companies in all quarters. Also, a few companies could not be found in CRSP and were deleted. I excluded events with low analyst coverage (less than three individual estimates) and low eps values (below 5 cents). The final sample for the underreaction test consists of 43680 earnings announcements. To capture investors' overreaction to past earnings surprises, EPS estimates and their actual values for each of the 4 preceding quarters (denoted respectively

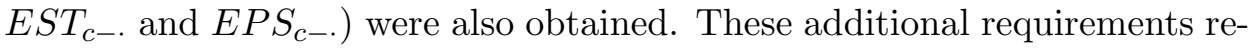
duce the number of available events for the overreaction tests to 18385 .

\subsection{Methodology}

\subsubsection{Computation of unexpected earnings}

As will be shown later, detecting overreaction to past earnings surprises requires a measure of the degree of consensus among analysts. For this reason, I use the latest consensus estimate before an announcement instead of the commonly used last individual estimate. For a given quarter $q$, unexpected earnings $\left(U E_{q}\right)$ equal the difference between actual earnings $\left(E P S_{q}\right)$ and the consensus estimate in the month preceding the actual announcement 
$\left(E S T_{q}\right):$

$$
U E_{q}=E P S_{q}-E S T_{q}
$$

\subsubsection{Scaling Unexpected Surprises}

For this study, I used two different scaling methods for unexpected earnings. The first, rather classical, consists of dividing the unexpected earnings by the actual earnings per share. ${ }^{3}$ The purpose of this methodology is to equally weight unexpected earnings for portfolio or event studies and allow for crosssectional comparison of all surprise and return variables. I calculate scaled unexpected earnings $\left(S C U E_{q}\right)$ by dividing unexpected earnings $\left(U E_{q}\right)$ by the reported eps $\left(E P S_{q}\right)$ :

$$
S C U E_{q}=\frac{U E_{q}}{a b s\left(E P S_{q}\right)}
$$

The second methodology is used to identify highly unexpected earnings. I compute standardized unexpected earnings $\left(S U E_{q}\right)$ by dividing the unexpected earnings $\left(U E_{q}\right)$ by the standard deviation of the consensus forecast $\left(\sigma_{E S T_{q}}\right)$. In this manner, I capture the degree to which analysts (and the market) agree on a given earnings estimate:

$$
S U E_{q}=\frac{U E_{q}}{\sigma_{E S T_{q}}}
$$

When analysts disagree on earnings forecasts, the standard deviation of estimates within a monthly consensus is high. In the extreme case of high uncertainty, that is, low consensus among analysts, the degree to which actual earnings are considered as unexpected (the $S U E$ measure) would be rather low. Conversely, the higher the consensus among analysts, the lower the consensus standard deviation, which results in a higher surprise for a given level of unexpected earnings. It follows that standardized unexpected earnings measure the strength in which the actual earnings differ from their estimate.

\footnotetext{
${ }^{3}$ Other methodologies use the share price as denominator. Although not reported, similar results were obtained.
} 


\subsection{Abnormal returns}

Daily abnormal returns are computed using a size-adjusted approach: for stock $i$ at time $t$, the daily abnormal return is defined by the difference between the stock's daily raw return and the equally weighted daily return of the size portfolio, the stock belongs to at the beginning of the year: ${ }^{4}$

$$
A R_{i, t}=R_{i, t}-\text { Size }_{t}
$$

where $R_{i, t}$ is stock $i$ 's daily return at time $t$ and $S i z e_{t}$ is the equally weighted daily return for the corresponding size portfolio.

Cumulative abnormal returns for stock $i$ in an event window $(p, q)$ are computed as follows:

$$
C A R_{i}(p, q)=\sum_{t=p}^{q} A R_{i, t}
$$

where $p$ and $q$ are the dates relative to the announcement date, denoted as 0 .

\subsection{Portfolio construction and statistical significance of ab- normal returns}

The tests presented hereafter rely on a sort ranking procedure, where each event is assigned to one of ten portfolios, portfolio 1 displaying the highest positive surprises and portfolio 10 the highest negative surprises. For the tests which focus on overreaction to a series of similar past surprises, we repeat the portfolio formation procedure backwards. The events contained in each portfolio, obtained at the first step, are, in a second step, ranked according to the earnings surprise of the preceding quarter and assigned to one of three portfolios (respectively positive, null and negative surprises). This procedure is repeated up to 4 times, yielding one current earnings surprise and 4 past surprises. This selection-rank methodology allows a progressive portfolio study, where consecutively formed portfolios only differ from their parent portfolio by the most ancient earnings surprise. This methodology

\footnotetext{
${ }^{4}$ The size of a company is calculated at the beginning of each year, by multiplying the share price by the number of shares outstanding. Each stock is then assigned to one of ten size-portfolios.
} 
allows to focus on the impact of the number of similar past earnings surprises on the market reaction to the most recent earnings announcement.

For most of the tests, a non parametric significance test, initiated by Foster, Olsen, and Shevlin (1984) and reviewed by Lyon, Barber, and Tsai (1999) is used. It relies on statistical significance levels which are drawn from an empirical sample distribution. Statistical significance is assessed by comparing the observed portfolio cumulated abnormal return $(C A R)$ with the empirical distribution of $C A R \mathrm{~s}$ for a companion sample. The empirical distribution is generated as follows:

1. For each event in the portfolio, randomly select one event in the parent population.

2. Compute equal weighted $C A R \mathrm{~s}$ for the companion sample.

3. Repeat steps 1 and 21500 times and rank the companion sample $C A R \mathrm{~s}$ from the lowest to the highest to obtain the empirical distribution.

This test has several appealing properties. It does not assume normality, it does not assume constant variance of security returns over time and it does not assume cross-sectional independence in the residuals. Moreover, as Lyon, Barber, and Tsai (1999) point out, unlike the conventional t-statistic, in which the null hypothesis is that the mean $C A R$ is zero, the null hypothesis by approximating the empirical distribution is that the mean $C A R$ equals the companion sample mean $C A R$.

\section{Investors' underreaction to earnings announce- ments}

Numerous empirical studies found significant abnormal returns for periods up to 480 days after earnings announcements. The anomaly, known as the Post-Earnings-Announcement-Drift has shown to be robust and is considered as one of the most challenging evidence against market efficiency.

To confirm the existence of a price drift after earnings announcements, I ranked all events into 10 portfolios, according to its current scaled unexpected earnings $\left(S C U E_{c}\right)$, portfolio 1 containing the highest positive surprises, portfolio 10 the highest negative surprises. Table 1 displays cumulated abnormal returns for different event windows for each portfolio. 
Table 1: Market reaction to current scaled unexpected earnings $\left(S C U E_{c}\right)$

\begin{tabular}{|c|c|c|c|c|c|}
\hline \multirow[b]{2}{*}{ Portfolio } & \multirow[b]{2}{*}{$S C U E_{c}$} & \multicolumn{4}{|c|}{ Event Windows } \\
\hline & & $\begin{array}{c}\mathrm{A} \\
(1 ; 3)\end{array}$ & $\begin{array}{c}\mathrm{B} \\
(1 ; 10)\end{array}$ & $\begin{array}{c}\mathrm{C} \\
(1 ; 30)\end{array}$ & $\begin{array}{c}\mathrm{D} \\
(1 ; 60)\end{array}$ \\
\hline 1 & 0.2260 & $2.36 \%^{* * * *}$ & $2.86 \%$ **** & $4.08 \%$ **** & $5.80 \%$ **** \\
\hline 2 & 0.0694 & $1.41 \%^{* * * *}$ & $1.79 \%$ **** & $2.20 \%$ **** & $2.42 \%$ **** \\
\hline 3 & 0.0345 & $0.89 \%^{* * * *}$ & $1.05 \%$ **** & $1.05 \%$ **** & $0.82 \%^{* * * *}$ \\
\hline 4 & 0.0128 & $0.38 \%$ **** & $0.55 \% * * *$ & $0.26 \%$ & $-0.56 \%$ \\
\hline 5 & 0.0000 & $-0.26 \%$ & $-0.29 \% \diamond \infty \diamond \diamond$ & $-0.24 \% \infty \%^{\infty}$ & $-0.74 \% \diamond \diamond \diamond \diamond$ \\
\hline 6 & -0.0073 & $-0.34 \%, 0<\infty$ & $-0.09 \% \diamond 0 \diamond$ & $-0.09 \% \diamond \diamond$ & $-0.78 \%, \diamond 0 \Delta$ \\
\hline 7 & -0.0315 & $-0.68 \%, 0<\diamond$ & $-0.55 \%, 000 \Delta$ & $-1.05 \%, \infty 0 \infty$ & $-2.13 \%^{\diamond 0 \Delta \diamond}$ \\
\hline 8 & -0.0683 & $-0.78 \%, 0000$ & $-0.78 \% \diamond \diamond \diamond \diamond$ & $-0.92 \%, \infty 0 \infty$ & $-1.69 \% \diamond \diamond \diamond \diamond$ \\
\hline 9 & -0.1528 & $-0.99 \%$ & $-1.08 \% \diamond \diamond \diamond \diamond$ & $-1.17 \%$ & $-1.75 \% \diamond \infty \Delta$ \\
\hline 10 & -0.7121 & $-1.42 \%, 0000$ & $-1.03 \%, \infty 0 \infty$ & $-1.24 \% \infty<\infty$ & $-1.61 \% \diamond \infty \Delta \diamond$ \\
\hline
\end{tabular}

The table above displays cumulated abnormal returns for different event windows and 10 portfolios, formed by sort-ranking all events according to their current scaled unexpected earnings. Portfolio 1 contains the highest positive surprises, portfolio 10 the highest negative surprises. $S U E_{c}$ denotes the average scaled unexpected earnings for a given portfolio.

The symbols $*, * *, * * *$, and $* * * *$ indicate that the measure is significantly higher than, respectively, $90 \%, 95 \%, 99 \%$, and $99,5 \%$ of a sample-wide empirical distribution.

The symbols $\diamond, \diamond \diamond, \diamond \diamond$, and $\diamond \diamond \diamond \diamond$ indicate that the measure is significantly lower than, respectively, $90 \%, 95 \%, 99 \%$, and $99,5 \%$ of a sample-wide empirical distribution.

The results confirm the existence of a slow price adjustment to unexpected earnings. With a few exceptions, cumulated abnormal returns increase steadily up to 60 days after the earnings announcement. The strategy which consists in buying portfolio 1 and short-selling portfolio 10 yields abnormal returns of $3.89 \%$ over the 10 days and $7.41 \%$ over the 60 days following the earnings announcement.

The results regarding market underreaction to unexpected earnings I obtained in this study are neither original, nor especially different from those found in the existing literature. What will be shown hereafter (section 4) is that while the use of scaled unexpected surprises $(S C U E)$ shows underreaction to current earnings surprises, the use of standardized unexpected earnings $(S U E)$ uncovers an overreaction phenomenon to past earnings surprises. 


\section{Investors' overreaction to past highly unex- pected surprises}

Investors, who exhibit representativeness, extrapolate their information too far into the future. As, on average, these extreme expectations are not confirmed by actual figures, one could expect subsequent reversals. Especially after highly unexpected surprises, investors are likely to overestimate future earnings surprises. On average, these important surprises should be followed, at the date of subsequent earnings announcement, by a correction of the initial overreaction, that is, by $C A R \mathrm{~s}$ of the opposite sign.

I formed 10 portfolios based on the previous quarter standardized unexpected surprise $S U E_{c-1}$. Results are presented in table 2 .

Table 2: Market Reaction Conditional on the Previous Standardized Unexpected Earnings $S U E_{c-1}$

\begin{tabular}{|c|c|c|c|c|c|}
\hline Portfolio & $S U E_{c-1}$ & $\begin{array}{c}\mathrm{A} \\
(0 ; 1)\end{array}$ & $\begin{array}{c}\mathrm{B} \\
(0 ; 3)\end{array}$ & $\begin{array}{c}\mathrm{C} \\
(0 ; 30)\end{array}$ & $\begin{array}{c}\mathrm{D} \\
(0 ; 60)\end{array}$ \\
\hline 1 & 0.0513 & $-0.73 \% \bowtie \diamond \diamond \diamond$ & $-0.95 \%$ & $-1.44 \%$ & $-2.37 \%$ \\
\hline 2 & 0.0178 & $-0.44 \%, 000 \diamond$ & $-0.65 \%, 000 \diamond$ & $-0.77 \%$ & $-1.44 \%, \infty>\infty \Delta$ \\
\hline 3 & 0.0104 & $-0.06 \% \diamond \diamond$ & $-0.20 \% \diamond \diamond \diamond$ & $-0.39 \%$ & $-1.19 \% \diamond \diamond \diamond \diamond$ \\
\hline 4 & 0.0048 & $0.06 \%$ & $-0.13 \%^{\diamond \diamond}$ & $-0.60 \% \diamond \diamond \diamond \diamond$ & $-1.31 \% \diamond \diamond \diamond \diamond$ \\
\hline 5 & 0.0004 & $0.05 \%$ & $0.09 \%$ & $0.35 \%$ & $-0.70 \% \diamond 0<0$ \\
\hline 6 & -0.0043 & $-0.13 \%$ & $-0.13 \% \bowtie \diamond$ & $0.03 \%$ & $-0.54 \%^{\diamond \diamond}$ \\
\hline 7 & -0.0091 & $0.57 \%^{* * * *}$ & $0.58 \%^{* * * *}$ & $0.83 \%^{* * *}$ & $0.38 \% *$ \\
\hline 8 & -0.0163 & $0.08 \%$ & $0.25 \%^{* *}$ & $0.18 \%$ & $-0.37 \%$ \\
\hline 9 & -0.0296 & $0.49 \%^{* * * *}$ & $0.61 \%^{* * * *}$ & $1.26 \%$ *** & $0.47 \%^{* *}$ \\
\hline 10 & -0.1061 & $1.11 \%^{* * * *}$ & $1.17 \%^{* * * *}$ & $1.76 \%$ *** & $1.58 \%^{* * * *}$ \\
\hline
\end{tabular}

The table shows cumulated abnormal returns for 10 portfolios formed according to the preceding quarter standardized unexpected earnings $\left(S U E_{c-1}\right)$ for different event windows. Each window $\mathrm{A}, \mathrm{B}, \mathrm{C}$ et $\mathrm{D}$ displays, in braces, the period (start date, end date), the announcement day being denoted day 0 .

The symbols $*,{ }^{* *},{ }^{* * *}$, and ${ }^{* * * *}$ indicate that the measure is significantly higher than, respectively, $90 \%, 95 \%, 99 \%$, and $99,5 \%$ of a sample-wide empirical distribution.

The symbols $\diamond, \diamond, \diamond \diamond \diamond$, and $\diamond \diamond \diamond \diamond$ indicate that the measure is significantly lower than, respectively, $90 \%, 95 \%, 99 \%$, and $99,5 \%$ of a sample wide empirical distribution.

The results displayed in table 2 are consistent with the overreaction hypothesis. It seems that investors rely too heavily on the information carried 
by a prior highly unexpected earnings surprise. After an important positive surprise $\left(S U E_{c-1}=0.0513\right.$ for portfolio 1$)$ investors are deceived by the current earnings surprise. For this portfolio, cumulated abnormal returns computed over the period following the current earnings announcement are negative, yielding $-0.73 \%$ for the first two trading days (including the day of announcement) and even $-2.37 \%$ over the 61 first trading days after the announcement.

For positive and negative surprise portfolios, computed $C A R \mathrm{~s}$ are of the opposite sign of the past earnings surprise, and generally significantly different from the mean value of a randomly generated sample-wide empirical distribution. Thus, a highly unexpected positive (negative) surprise is, on average, followed by a reversal, that is, negative (positive) abnormal returns at the time of the subsequent earnings announcement.

\subsection{Market reaction to null surprises}

The results presented above indicate that an extreme earnings surprise is followed, at the time of the subsequent earnings announcement, by a market reaction of the opposite sign to the initial surprise. These findings suggest the presence of investors' overreaction to earnings surprises. If this overreaction is due to representativeness, then investors would not only extrapolate a given earnings surprise into the future (and end up disappointed when the subsequent actual earnings figures are announced), but also misreact more heavily to a series of similar surprises. Hence, I expect the reversal to be more pronounced for events with long series of good or bad earnings surprises.

To ascertain wether these abnormal returns are due to investors misperception of past earnings surprises and not related to the current unexpected earnings, the following tests focus on a portfolio, composed of recent null surprises. ${ }^{5}$ If any subset of this sample exhibits $C A R$ s significantly different from the parents portfolio, they might be related to previous earnings surprises.

\footnotetext{
${ }^{5}$ The use of events with exact matching of estimates and eps values (zero surprise events) was not possible due to IBES split adjustment problems. I thank Jakob Thomas for that helpful remark.
} 
Using a sequential sort-ranking procedure, all null-surprise events (recent-surprise-portfolio 5) are ranked according to the most recent past standardized unexpected earnings $\left(S U E_{c-1}\right)$ and assigned to one of three equal sized portfolios (positive, null, and negative $c-1$ surprise portfolios). Each of those portfolios is divided again into three subportfolios, based on the standardized unexpected earnings, that lie two quarters behind $\left(S U E_{c-2}\right)$. I repeat this procedure to obtain 5 consecutive quarters $\left(S U E_{c}\right.$ until $\left.S U E_{c-4}\right)$. This procedure identifies events with a series of similar past earnings surprises, while keeping the most recent surprise $S U E_{c}$ close to zero. If the overreaction hypothesis holds, I should find significant abnormal returns of the opposite sign to the initial series of unexpected earnings: the longer the series of past similar surprises, the higher the subsequent reversal.

Table 3: Market Reaction Conditional on Previous Earnings Surprises

\begin{tabular}{|c|c|c|c|c|c|c|}
\hline Portfolio & SUE $c$ & $\begin{array}{r}\text { Sample } \\
\text { Size } \\
\end{array}$ & $\begin{array}{c}\mathrm{A} \\
(0 ; 1) \\
\end{array}$ & $\begin{array}{c}\text { B } \\
(0 ; 3)\end{array}$ & $\begin{array}{c}\mathrm{C} \\
(0 ; 30) \\
\end{array}$ & $\begin{array}{c}\mathrm{D} \\
(0 ; 60) \\
\end{array}$ \\
\hline $5,1,1,1,1$ & 0.0026 & 18 & $0.23 \%$ & $1.54 \%$ & $-9.80 \% \diamond \diamond \diamond \diamond$ & $-5.48 \%$ \\
\hline $5,1,1,1$ & 0.0006 & 48 & $-0.23 \%$ & $-1.28 \%$ & $-5.30 \% \diamond$ & $-6.04 \% \diamond$ \\
\hline $5,1,1$ & 0.0001 & 160 & $-1.19 \%$ & $-2.00 \% \diamond \diamond \diamond$ & $-3.74 \% \diamond \diamond \diamond \diamond$ & $-4.14 \%, 0000$ \\
\hline 5,1 & 0.0000 & 478 & $-0.95 \% \diamond \diamond \diamond \diamond$ & $-1.41 \%^{\diamond \diamond \diamond \diamond}$ & $-1.68 \% \diamond \diamond \diamond \diamond$ & $-1.93 \% \diamond \diamond \diamond 0$ \\
\hline 5 & 0.0000 & 1443 & $-0.12 \%$ & $-0.41 \%$ & $0.34 \%$ & $-0.84 \%$ \\
\hline 5,3 & 0.0001 & 514 & $0.82 \%^{* * * *}$ & $0.62 \%^{* * * *}$ & $1.44 \%^{* * * *}$ & $0.94 \%^{* * * *}$ \\
\hline $5,3,3$ & 0.0001 & 167 & $1.40 \%$ **** & $1.19 \%^{* * *}$ & $2.07 \%^{*}$ & $2.23 \%^{* *}$ \\
\hline $5,3,3,3$ & 0.0001 & 54 & $1.74 \% *$ & $0.71 \%$ & $1.78 \%$ & $3.96 \% *$ \\
\hline $5,3,3,3,3$ & 0.0000 & 18 & $1.16 \%$ & $0.83 \%$ & $2.60 \%^{*}$ & $0.61 \%$ \\
\hline
\end{tabular}

The table shows that cumulated abnormal returns, computed for different event windows, are increasing in the length of a past earnings surprise series. All portfolios are formed sequentially starting from the current null surprise (portfolio 5), then forming, at each step, 3 portfolios based on the preceding standardized unexpected earnings.

Cumulated abnormal returns are computed for the first two trading days including the announcement day (event window A), the period covering the first four trading days (B), 31 trading days (C), and 61 trading days including the earnings announcement.

The symbols $*,^{* *}, * * *$, and ${ }^{* * *}$ indicate that the measure is significantly higher than, respectively, $90 \%, 95 \%, 99 \%$, and $99,5 \%$ of the empirical distribution generated from the companion portfolio composed of all events, that differ only in the most ancient standardized unexpected earnings.

The symbols $\diamond, \diamond \diamond, \diamond \diamond$, and $\diamond \diamond \diamond \diamond$ indicate that the measure is significantly lower than, respectively, $90 \%, 95 \%, 99 \%$, and $99,5 \%$ of the empirical distribution generated from the companion portfolio composed of all events, that differ only in the most ancient standardized unexpected earnings.

As all events display, on average, a current null surprise, there should 
be no significant market reaction to this announcement. However, extreme past surprise portfolios exhibit a strong correction pattern: cumulated abnormal returns are globally negative for prior positive surprises and globally positive for prior negative surprises. My understanding is that investors overreact to past highly unexpected earnings and only correct their extreme belief at the date of subsequent earnings announcement. Moreover, this correction is stronger for a long series of similar consecutive earnings surprises. For example, portfolio denoted 5,1,1,1,1, having experienced a series of four positive past surprises and a current null surprise, displays a negative cumulated abnormal return of $-9.80 \%$ over the first 31 trading days after the announcement. For the specific event window C, this portfolio significantly outperforms portfolio $5,1,1,1$, with only three consecutive positive past earnings surprises and displaying a lower correction (cumulated abnormal returns equal $-5.30 \%$ ). Similar, although less striking results are obtained for prior negative surprises, which are followed by a reversal that strengthens with the length of the series of prior negative surprises.

Recall that those earnings announcements are actually null surprises, that is, the current earnings figures match, on average, analysts' estimates. Similar results are obtained for portfolios with prior negative surprises; displaying positive abnormal returns after the current null-surprise, increasing in the number of similar past surprises.

These results indicate that the longer the series of similar earnings surprises (standardized unexpected earnings in this test), the stronger the subsequent correction. This evidence is consistent with the idea that representativeness causes investors to overreact more heavily to a series of similar information. As these beliefs are not confirmed by actual earnings figures, the market returns experience a strong reversal. Latter is increasing in the length of the series of similar earnings surprises.

\section{Conclusions}

Two families of pervasive anomalies have emerged from empirical work in the field of what is commonly called Behavioral Finance. While underreaction defines a slow adjustment of prices to corporate events or announcements, 
overreaction deals with extreme stock price reactions to previous information or past performance. Theoretical models have shown that both phenomena find potential explanations in cognitive biases, that is, investor irrationality.

In this study, I confirm the existence of post-earnings announcement underreaction and provide new evidence of overreaction to highly unexpected past earnings surprises. Traditionally, unexpected earnings are defined by the difference between the last individual or consensus estimate and the actual, reported earnings per share, standardized by the share price. Other methodologies include scaling by the actual eps or the forecast made. While former is a measure of the market surprise, latter can be considered as the analyst's proportional estimation error. In order to capture the extent to which an earnings surprise is highly unexpected, some of the tests performed in this study use the standard deviation of consensus forecasts as a scaling factor.

The results suggest that investors simultaneously exhibit short-term underreaction to earnings announcements and long-term overreaction to past highly unexpected earnings. A potential explanation for the reported overreaction phenomenon is the representativeness bias. As I show, the overreaction and the later reversal is stronger for events, which exhibit a long series of similar past earnings surprises. 


\section{References}

Ball, R. and P. Brown (1968). An empirical evaluation of accounting income numbers. Journal of Accounting Research 6, 159-178.

Barberis, N., A. Shleifer, and R. Vishny (1998). A model of investor sentiment. Journal of Financial Economics 49, 307-343.

Bhojraj, S. and B. Swaminathan (2001). Macromomentum: Evidence of predictability in international equity markets. Cornell University.

Chan, K., A. Hameed, and W. Tong (2000). Profitability of momentum strategies in the international equity markets. Journal of Financial and Quantitative Analysis 35, 153-172.

Chopra, N., J. Lakonishok, and J. Ritter (1992). Measuring abnormal performance: Do stocks overreact? Journal of Financial Economics 31-2, 235-268.

Chui, A., S. Titman, and K. Wei (2000). Momentum, legal systems and ownership structure: An analysis of asian stock markets. Hong Kong University of Science and Technology.

Cutler, D., J. Poterba, and L. Summers (1991). Speculative dynamics. Review of Economics Studies 58, 529-546.

Daniel, K., D. Hirshleifer, and A. Subrahmanyam (1998). Investor psychology and security market under and overreactions. Journal of Finance 53, 1839-1885.

Daniel, K. and S. Titman (1999). Market efficiency in an irrational world. Financial Analysts' Journal 55/6, 28-40.

De Bondt, W. and R. Thaler (1985). Does the stock market overreact? Journal of Finance 40, 793-805.

(1987). Further evidence on investor overreaction and stock market seasonality. Journal of Finance 42, 557-581.

Easterwood, J. and S. Nutt (1999). Inefficiency in analysts' earnings forecasts: Systematic misreaction or systematic optimism? Journal of Finance 54-5, 1777 - 1797. 
Foster, G., C. Olsen, and T. Shevlin (1984). Earnings releases, anomalies and the behavior of security returns. Accounting Review 59-4, 574-603.

Grinblatt, M. and T. Moskowitz (1999). The cross section of expected returns and its relation to past returns: New evidence. UCLA Anderson School of Management.

Hirshleifer, D., J. Myers, L. Myers, and S. Teoh (2003). Do individual investors drive post-earnings announcement drift? Dice Center Working Paper Series.

Hong, H., T. Lim, and J. Stein (2000). Bad news travel slowly: Size, analyst coverage and the profitability of momentum strategies. Journal of Finance 55, 265-295.

Hong, H. and J. Stein (1999). A unified theory of underraction, momentum trading and overreaction in asset markets. Journal of Finance 54-6, 2143-2184.

Jegadeesh, N. and S. Titman (1993). Returns to buying winners and selling losers: Implications for stock market efficiency. Journal of Finance 48-1, 65-91. (2001). Profitability of momentum strategies: An evaluation of alternative explanations. Journal of Finance 56, 699-720.

Lee, C. and B. Swaminathan (2000). Do stock prices overreact to earnings news? Parker Center, Cornell University.

Lewellen, J. (2002). Momentum and autocorrelation in stock returns. Review of Financial Studies 15, 533-563.

Lyon, J., B. Barber, and C. Tsai (1999). Improved methods for tests of long-run abnormal returns. Journal of Financial Economics 54, 165-201.

Poteshman, A. (2001). Underreaction, overreaction and increasing misreaction to information in the options market. Journal of Finance 56-3, 851-876. 
Sadka, R. (2005). Momentum and post-earnings-announcement drift anomalies: The role of liquidity risk. Working Paper.

Shleifer, A. (2000). Inefficient markets. Oxford University Press. 